\title{
Towards an improvement of the geoid model in Japan by GOCE data: A case study of the Shikoku area
}

\author{
Patroba Achola Odera and Yoichi Fukuda \\ Graduate School of Science, Kyoto University, Kitashirakawa Oiwake-cho, Sakyo-ku, Kyoto 606-8502, Japan
}

(Received May 14, 2012; Revised July 9, 2012; Accepted July 10, 2012; Online published May 7, 2013)

\begin{abstract}
The performance of the recently-released global geopotential models (GGMs) based on 2, 8 and 12 months of data collected by the Gravity field and steady-state Ocean Circulation Explorer (GOCE) is evaluated using geoid undulations and free-air gravity anomalies over Japan. Comparisons over the four main islands reveal that EGM2008 performs better than GOCE and related GGMs in Hokkaido, Honshu and Kyushu. However, GOCE and related GGMs perform better than EGM2008 in Shikoku. GOCO02S, GOCE-DIR3 and GOCE-TIM3 have a similar performance, and the best, in Shikoku. Given that GOCE-TIM3 relies exclusively on GOCE data, it is assessed further for geoid determination in Shikoku. To evaluate the actual improvement of the geoid model in the Shikoku area by GOCE-TIM3, the geoid over Shikoku is determined from EGM2008 and a combination of GOCE-TIM3 with EGM2008. There is an improvement in the standard deviation from $\pm 8.7 \mathrm{~cm}$, when EGM2008 is used, to $\pm 6.6 \mathrm{~cm}$, when GOCE-TM3/EGM2008 is used. The first improvement of the geoid model over Japan by GOCE data is evident in Shikoku.
\end{abstract}

Key words: Geoid model, gravity, GOCE, EGM2008.

\section{Introduction}

Geoid modelling over Japan remains a challenge, especially with respect to the establishment of a consistent vertical datum. The last decade has seen a concerted effort towards the realisation of a precise geoid model over Japan (e.g. Kuroishi et al., 2002; Kuroishi and Keller, 2005; Kuroishi, 2009; Odera et al., 2012).

Several global geopotential models (GGMs), both combined and satellite only, exist today. The evaluation of the performance of GGMs is necessary for the selection of an optimal model for geoid determination. Some of the GGMs that have been used for geoid modelling in Japan include OSU91A (Rapp et al., 1991), EGM96 (Lemoine et al., 1997), GGM02C (Tapley et al., 2005) and EGM2008 (Pavlis et al., 2008). However, EGM2008 performs better than the other mentioned GGMs over Japan.

Recently, a number of GGMs based on the data collected by the Gravity field and steady-state Ocean Circulation Explorer (GOCE) have been released. Some of the evaluations of GOCE GGMs can be found in Janák and Pitoňák (2011), Hirt et al. (2011) and Gruber et al. (2011). We evaluate the performance of the recently-released GGMs based on 2, 8 and 12 months of data collected by GOCE using geoid undulations and free-air gravity anomalies over Japan. Further evaluations are carried out over each of the four main islands. However, Honshu is divided into three parts (north, central and west) because of its size and geometry. This kind of sub-regional evaluation of GGMs is being tested

Copyright (c) The Society of Geomagnetism and Earth, Planetary and Space Sciences (SGEPSS); The Seismological Society of Japan; The Volcanological Society of Japan; The Geodetic Society of Japan; The Japanese Society for Planetary Sciences; TERRAPUB.

doi:10.5047/eps.2012.07.005 over Japan for the first time. The evaluated GOCE and related GGMs include GOCE-DIR1, 2, 3 (Bruinsma et al., 2010; Pail et al., 2011), GOCE-TIM1, 2, 3 (Pail et al., 2010b, 2011), GOCE-SPW1, 2 (Migliaccio et al., 2011) and GOCO01S, 02S (Pail et al., 2010a; Goiginger et al., 2011). From the preliminary evaluations over Japan, it is found that GOCE and related GGMs can improve the geoid model over Shikoku.

To determine the actual improvement, two geoid models are computed over Shikoku using EGM2008 and GOCETIM3/EGM2008. In both cases, the same terrestrial gravity data sets are used. The Stokes-Helmert scheme in a modified form is applied for the determination of the geoid, using an empirically-determined optimal spherical cap-size, and Kriging is used for gridding the residual gravity anomalies. The standard deviation of the differences between gravimetric and GPS/levelling geoid undulations is used to assess the two geoid models. The results of the evaluations are presented. The paper concludes with a comparison of the derived gravimetric and GPS/levelling geoid undulations over Shikoku.

\section{Evaluation of GGMs}

The distribution of GPS/levelling and first-order gravity data over the four main islands is given in Fig. 1. The number of GPS/levelling and first-order gravity data in the six sub-regions is given in Table 1 . A preliminary evaluation of GGMs based on 2 and 8 months of GOCE data over Japan shows improvement by GOCE-release 2 ( 8 months data) compared to GOCE-release 1 (2 months data) in Japan. However, GOCE-DIR1 performs better than GOCE-DIR2 over Japan. Similar results have been observed over Central Europe (Janák and Pitoňák, 2011). Therefore, only re- 
Table 1. Number of GPS/levelling and first-order gravity data points in six sub-regions of Japan.

\begin{tabular}{lrrrrrrr}
\hline Data & Hokkaido & $\begin{array}{r}\text { North } \\
\text { Honshu }\end{array}$ & $\begin{array}{r}\text { Central } \\
\text { Honshu }\end{array}$ & $\begin{array}{r}\text { West } \\
\text { Honshu }\end{array}$ & Shikoku & Kyushu & Whole \\
\hline GPS/lev & 163 & 171 & 163 & 158 & 56 & 105 & 816 \\
Gravity & 1,431 & 1,368 & 1,620 & 1,166 & 401 & 965 & 6,951 \\
\hline
\end{tabular}

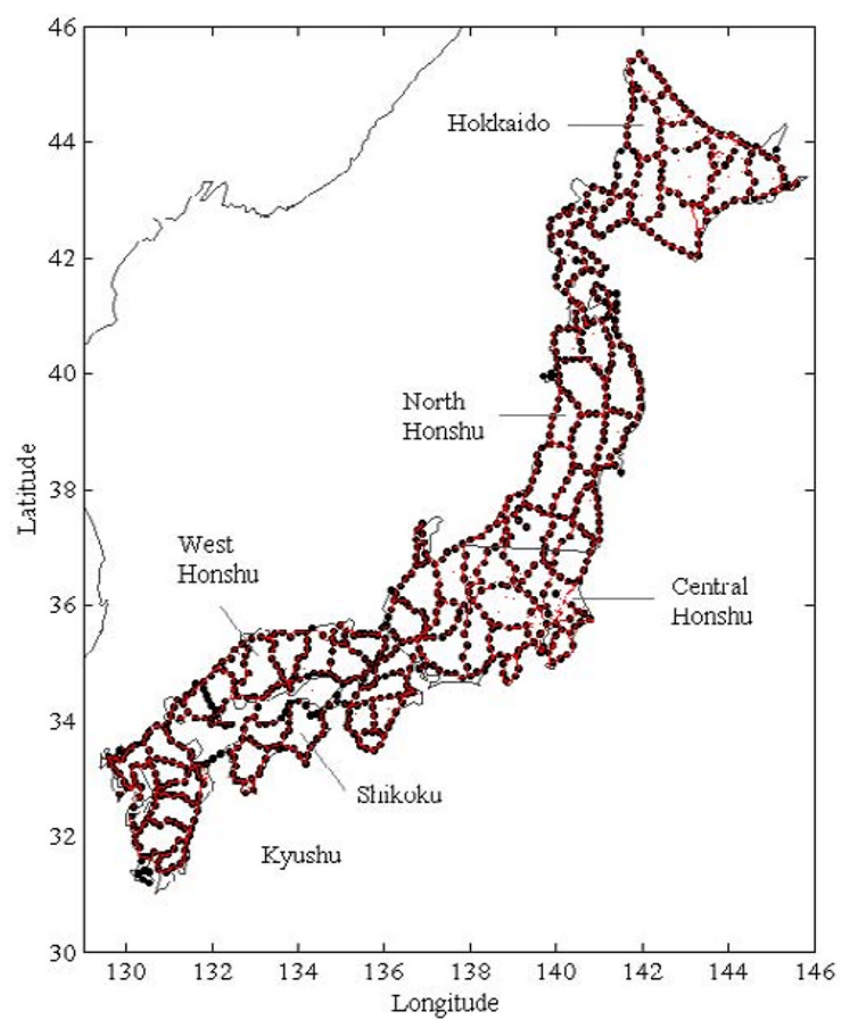

Fig. 1. Distribution of GPS/levelling (big black dots) and first-order gravity (small red dots) data over the four main islands.

leases 2 and 3 of GOCE-related GGMs and GOCE-DIR1 are considered for detailed evaluation. The standard deviations of the differences between GPS/levelling, and GGMsimplied, geoid undulations are given in Table 2, while the standard deviations of the differences between the observed, and the GGMs-implied, free-air gravity anomalies are given in Table 3. In these tables, all the models are truncated to 150, 180, 210 and 240 degrees.

In summary, the performance of EGM2008 and GOCErelated GGMs over Japan is practically the same at 150 degrees, although EGM2008 performs better at the spectral bands 180, 210 and 240 degrees. GOCE-TIM3 performs better than GOCE-TIM2 over Japan. Although GOCEDIR3 performs better than GOCE-DIR2, it still performs slightly below GOCE-DIR1 over Japan. It only offers an improvement at 180 degrees, but the accuracy degenerates at the higher degrees. It should be noted that GOCE-DIR1, 2 and 3 are different in terms of the background data sets involved. Hence, the results of the comparisons over Japan are not so strange.

The comparisons over the four main islands reveal that EGM2008 performs better than GOCE, and related GGMs, in Hokkaido, Honshu and Kyushu. The good performance of EGM2008 over most parts of Japan may be attributed to the inclusion of terrestrial gravity data in the development of EGM2008. However, GOCE, and related GGMs, perform better than EGM2008 in Shikoku. We therefore suspect errors in the gravity data included in EGM2008 from the Shikoku area. GOCE-TIM3, GOCO02S and GOCEDIR3 have a similar, and better, performance in Shikoku. Given that GOCE-TIM3 relies exclusively on GOCE data, it is considered for geoid determination in Shikoku.

\section{Geoid Determination over Shikoku}

To evaluate the actual improvement of the geoid model in the Shikoku area by GOCE-TIM3, the geoid in Shikoku is determined from EGM2008 (up to 2, 190 degrees) and a combination of GOCE-TIM3 (up to 180 degrees) with EGM2008 (from 181 to 2, 190 degrees), that is, GOCETIM3/EGM2008. Stokes's integral formula for geoid determination (Stokes, 1849; Heiskanen and Moritz, 1967) has been used. A modified Stokes's formula, excluding small errors due to the ellipsoidal effects, is given as,

$$
N=N_{\mathrm{GGM}}+\frac{R}{4 \pi \gamma} \iint_{\sigma_{o}} \Delta g^{r} S^{\mathrm{ME}}(\psi) d \sigma+N_{\mathrm{ind}},
$$

where $N$ is the gravimetric geoid undulation, $N_{\mathrm{GGM}}$ is the geoid undulation obtained from EGM2008 or GOCETIM3/EGM2008 after applying the zero-degree term (with respect to GRS80), $\Delta g^{r}$ is the residual gravity anomaly, 
Table 2. Standard deviations of the differences between GPS/levelling and GGMs-implied geoid undulations in Japan (units in cm), $n$ represents the spherical harmonic degrees.

\begin{tabular}{|c|c|c|c|c|c|c|c|}
\hline GGM & Hokkaido & $\begin{array}{r}\text { North } \\
\text { Honshu }\end{array}$ & $\begin{array}{l}\text { Central } \\
\text { Honshu }\end{array}$ & $\begin{array}{r}\text { West } \\
\text { Honshu }\end{array}$ & Shikoku & Kyushu & Whole \\
\hline \multicolumn{8}{|l|}{$n=150$} \\
\hline EGM2008 & 101.3 & 66.3 & 98.2 & 93.0 & 73.5 & 43.3 & 88.4 \\
\hline DIR1 & 101.1 & 67.7 & 98.7 & 90.8 & 72.0 & 42.4 & 88.0 \\
\hline DIR2 & 101.5 & 66.5 & 99.5 & 91.7 & 71.2 & 43.3 & 88.4 \\
\hline DIR3 & 101.4 & 66.4 & 99.6 & 92.2 & 71.2 & 43.5 & 88.5 \\
\hline SPWS 2 & 101.2 & 66.3 & 99.1 & 91.3 & 71.1 & 43.6 & 88.0 \\
\hline TIM2 & 101.6 & 66.3 & 99.3 & 91.6 & 71.1 & 43.6 & 88.3 \\
\hline TIM3 & 101.4 & 66.1 & 99.5 & 92.3 & 70.8 & 43.6 & 88.4 \\
\hline GOCO02S & 101.3 & 66.1 & 99.1 & 92.2 & 70.8 & 43.3 & 88.3 \\
\hline \multicolumn{8}{|l|}{$n=180$} \\
\hline EGM2008 & 75.2 & 53.6 & 60.9 & 71.3 & 61.0 & 43.2 & 64.7 \\
\hline DIR1 & 75.6 & 55.7 & 61.3 & 72.0 & 60.0 & 45.2 & 65.4 \\
\hline DIR2 & 77.7 & 53.7 & 63.0 & 70.5 & 59.4 & 45.8 & 65.7 \\
\hline DIR3 & 77.2 & 53.9 & 62.3 & 70.3 & 57.6 & 43.6 & 65.1 \\
\hline SPWS 2 & 77.7 & 55.0 & 63.1 & 70.1 & 59.0 & 45.0 & 65.8 \\
\hline TIM2 & 77.8 & 53.8 & 62.7 & 70.3 & 59.6 & 45.5 & 65.7 \\
\hline TIM3 & 76.9 & 54.1 & 62.7 & 70.5 & 58.1 & 44.3 & 65.4 \\
\hline GOCO02S & 77.3 & 54.0 & 62.9 & 70.3 & 58.6 & 45.7 & 65.6 \\
\hline \multicolumn{8}{|l|}{$n=210$} \\
\hline EGM2008 & 63.9 & 51.6 & 55.3 & 52.7 & 43.2 & 39.1 & 54.7 \\
\hline DIR1 & 64.0 & 53.1 & 56.4 & 54.2 & 42.7 & 42.2 & 55.8 \\
\hline DIR2 & 67.0 & 52.0 & 58.3 & 53.8 & 41.6 & 42.8 & 56.6 \\
\hline DIR3 & 66.4 & 53.7 & 56.5 & 53.0 & 41.8 & 39.3 & 56.0 \\
\hline SPWS 2 & 68.0 & 53.1 & 57.5 & 57.2 & 43.9 & 39.7 & 57.6 \\
\hline TIM2 & 68.2 & 52.3 & 57.4 & 52.9 & 42.3 & 41.7 & 56.6 \\
\hline TIM3 & 66.5 & 52.7 & 56.2 & 52.9 & 42.1 & 40.2 & 55.9 \\
\hline GOCO02S & 67.8 & 52.3 & 57.7 & 53.4 & 42.0 & 41.8 & 56.6 \\
\hline \multicolumn{8}{|l|}{$n=240$} \\
\hline EGM2008 & 56.4 & 42.6 & 54.2 & 42.9 & 41.5 & 31.0 & 48.4 \\
\hline DIR1 & 56.6 & 45.7 & 55.9 & 45.3 & 42.6 & 32.8 & 50.0 \\
\hline DIR2 & 65.3 & 41.0 & 59.7 & 45.3 & 41.8 & 43.1 & 52.9 \\
\hline DIR3 & 61.2 & 44.3 & 56.6 & 48.4 & 41.2 & 34.7 & 51.6 \\
\hline SPWS 2 & 67.1 & 49.6 & 57.4 & 54.4 & 42.6 & 38.7 & 56.1 \\
\hline TIM2 & 63.9 & 42.8 & 59.1 & 45.6 & 40.9 & 38.6 & 52.5 \\
\hline TIM3 & 60.1 & 43.0 & 57.8 & 47.2 & 41.9 & 34.8 & 51.3 \\
\hline GOCO02S & 63.6 & 43.0 & 59.3 & 46.3 & 40.7 & 38.8 & 52.6 \\
\hline
\end{tabular}

$N_{\text {ind }}$ is the indirect effect on the geoid due to gravity reduction, and $S^{\mathrm{ME}}(\psi)$ is the Meissl's modified kernel (Meissl, 1971).

A description of gravity data used in this study can be found in Odera et al. (2012). The direct terrain effects (DTE), and the primary indirect terrain effects (PITE), are computed by the integral formulae proposed by Martinec and Vaníček (1994a, b) using a 50-m digital elevation model. The Kriging technique (Krige, 1951) is used for gridding residual gravity anomalies on a 1 by 1.5 arc-minute grid. A spherical cap-size of $40 \mathrm{~km}$ is adopted for the computations, after empirical evaluations. It should be noted that the classical Moritz formula (Moritz, 1980) and a planar formula (Wichiencharoen, 1982) are used for the computation of DTE and PITE, respectively, in the previous geoid model for Japan (Odera et al., 2012).

The comparisons are carried out using 56 GPS/levelling points in Shikoku. Let the two geoid models developed using EGM2008 and GOCE-TIM3/EGM2008, incorporating the contribution of the local gravity data, be referred to as geoid models A and B, respectively. Figure 2 shows the differences between the gravimetric geoid (A) and the GPS/levelling geoid undulations, while Fig. 3 represents the differences between the gravimetric geoid (B) and the GPS/levelling geoid undulations in Shikoku area. The statistics of the differences between gravimetric and GPS/levelling geoid undulations in Shikoku for the two geoid models are given in Table 4.

It can be seen from Table 4, that GOCE is already capable of improving the geoid model in the Shikoku area after 12 months of observations. There is an improvement in the standard deviation from $\pm 8.65 \mathrm{~cm}$ (for geoid model A) to $\pm 6.56 \mathrm{~cm}$ (for geoid model B), representing an improvement of $24.2 \%$. A similar comparison using the previous geoid model for Japan (Odera et al., 2012) gives a standard deviation of $\pm 8.69 \mathrm{~cm}$ over Shikoku. This means that the 
Table 3. Standard deviations of the differences between observed and GGMs-implied free-air gravity anomalies in Japan (units in mGal), $n$ represents the spherical harmonic degrees.

\begin{tabular}{|c|c|c|c|c|c|c|c|}
\hline GGM & Hokkaido & $\begin{array}{r}\text { North } \\
\text { Honshu }\end{array}$ & $\begin{array}{l}\text { Central } \\
\text { Honshu }\end{array}$ & $\begin{array}{r}\text { West } \\
\text { Honshu }\end{array}$ & Shikoku & Kyushu & Whole \\
\hline \multicolumn{8}{|l|}{$n=150$} \\
\hline EGM2008 & 41.6 & 27.0 & 40.2 & 33.5 & 27.8 & 18.4 & 35.7 \\
\hline DIR1 & 41.5 & 27.4 & 40.4 & 33.1 & 27.5 & 18.5 & 35.7 \\
\hline DIR2 & 41.6 & 27.2 & 40.4 & 33.2 & 27.5 & 18.4 & 35.7 \\
\hline DIR3 & 41.6 & 27.2 & 40.4 & 33.3 & 27.6 & 18.3 & 35.7 \\
\hline SPWS 2 & 41.6 & 27.2 & 40.4 & 33.1 & 27.5 & 18.4 & 35.7 \\
\hline TIM2 & 41.6 & 27.1 & 40.4 & 33.2 & 27.5 & 18.4 & 35.7 \\
\hline TIM3 & 41.6 & 27.1 & 40.4 & 33.3 & 27.6 & 18.3 & 35.7 \\
\hline GOCO02S & 41.5 & 27.1 & 40.5 & 33.4 & 27.5 & 18.3 & 35.7 \\
\hline \multicolumn{8}{|l|}{$n=180$} \\
\hline EGM2008 & 37.1 & 26.1 & 40.1 & 28.5 & 24.1 & 21.4 & 33.0 \\
\hline DIR1 & 37.3 & 26.3 & 40.2 & 28.7 & 23.6 & 21.8 & 33.2 \\
\hline DIR2 & 37.7 & 26.2 & 40.3 & 28.3 & 24.0 & 21.8 & 33.3 \\
\hline DIR3 & 37.6 & 26.2 & 40.3 & 28.4 & 24.0 & 21.5 & 33.2 \\
\hline SPWS 2 & 37.7 & 26.3 & 40.3 & 28.4 & 23.8 & 21.5 & 33.3 \\
\hline TIM2 & 37.8 & 26.2 & 40.4 & 28.3 & 24.0 & 21.8 & 33.3 \\
\hline TIM3 & 37.6 & 26.2 & 40.3 & 28.4 & 24.1 & 21.6 & 33.2 \\
\hline GOCO02S & 37.6 & 26.2 & 40.5 & 28.3 & 24.1 & 21.8 & 33.3 \\
\hline \multicolumn{8}{|l|}{$n=210$} \\
\hline EGM2008 & 34.5 & 27.4 & 41.9 & 25.7 & 23.5 & 22.0 & 32.5 \\
\hline DIR1 & 34.6 & 27.7 & 42.3 & 26.2 & 23.3 & 22.6 & 32.8 \\
\hline DIR2 & 35.4 & 27.8 & 42.4 & 26.1 & 22.2 & 21.8 & 32.9 \\
\hline DIR3 & 35.1 & 28.0 & 42.0 & 25.7 & 23.0 & 21.7 & 32.7 \\
\hline SPWS 2 & 35.4 & 27.3 & 41.8 & 26.2 & 23.1 & 21.0 & 32.7 \\
\hline TIM2 & 35.6 & 27.8 & 42.3 & 25.7 & 22.7 & 21.7 & 32.9 \\
\hline TIM3 & 35.0 & 27.8 & 41.9 & 25.7 & 23.1 & 21.8 & 32.7 \\
\hline GOCO02S & 35.4 & 27.7 & 42.4 & 25.8 & 22.9 & 21.7 & 32.9 \\
\hline \multicolumn{8}{|l|}{$n=240$} \\
\hline EGM2008 & 32.5 & 26.1 & 42.1 & 23.3 & 26.2 & 20.5 & 31.4 \\
\hline DIR1 & 32.7 & 26.8 & 42.4 & 24.2 & 26.7 & 20.9 & 31.9 \\
\hline DIR2 & 35.1 & 25.9 & 43.4 & 24.8 & 24.5 & 21.6 & 32.6 \\
\hline DIR3 & 34.0 & 26.5 & 42.6 & 25.0 & 24.3 & 20.8 & 32.2 \\
\hline SPWS 2 & 35.3 & 26.6 & 41.6 & 25.7 & 22.9 & 21.0 & 32.4 \\
\hline TIM2 & 34.6 & 25.8 & 43.0 & 24.7 & 23.8 & 20.8 & 32.3 \\
\hline TIM3 & 33.6 & 26.1 & 42.8 & 25.0 & 24.3 & 20.6 & 32.1 \\
\hline GOCO02S & 34.5 & 25.9 & 43.1 & 24.9 & 23.9 & 20.8 & 32.3 \\
\hline
\end{tabular}

Table 4. Statistics of the differences between gravimetric and GPS/levelling geoid undulations in Shikoku for geoid models A and B (units in cm).

\begin{tabular}{crrrr}
\hline Geoid model & Minimum & Maximum & Mean & SD \\
\hline A & -15.71 & 30.16 & -1.34 & 8.65 \\
B & -13.56 & 26.81 & -0.32 & 6.56 \\
\hline
\end{tabular}

use of integral formulae for computing DTE and PITE gives a very slight improvement in the geoid model over Shikoku, probably due to the low elevation (less than 2,000 m).

The differences between gravimetric and the GPS/levelling geoid undulations are smoother for geoid model B than geoid model A, as shown in Fig. 3 and Fig. 2, respectively. We suspect that the relatively low performance of EGM2008 in Shikoku is partly due to errors in the terrestrial gravity data, included in the development of EGM2008, from the Shikoku area.

\section{Conclusions}

The performance of the recently-released GOCE and related GGMs is evaluated over Japan as a whole, and in the sub-regions, using GPS/levelling geoid undulations and free-air gravity anomalies. The performance of EGM2008 and GOCE-related GGMs over Japan is comparable, although EGM2008 generally performs better than the GOCE-related GGMs over Japan. It is noted that the performance of EGM2008 and GOCE-related GGMs is practically the same over Japan at 150 degrees. Comparisons over the four main Japanese islands show that GOCE and related GGMs perform better than EGM2008 in the 


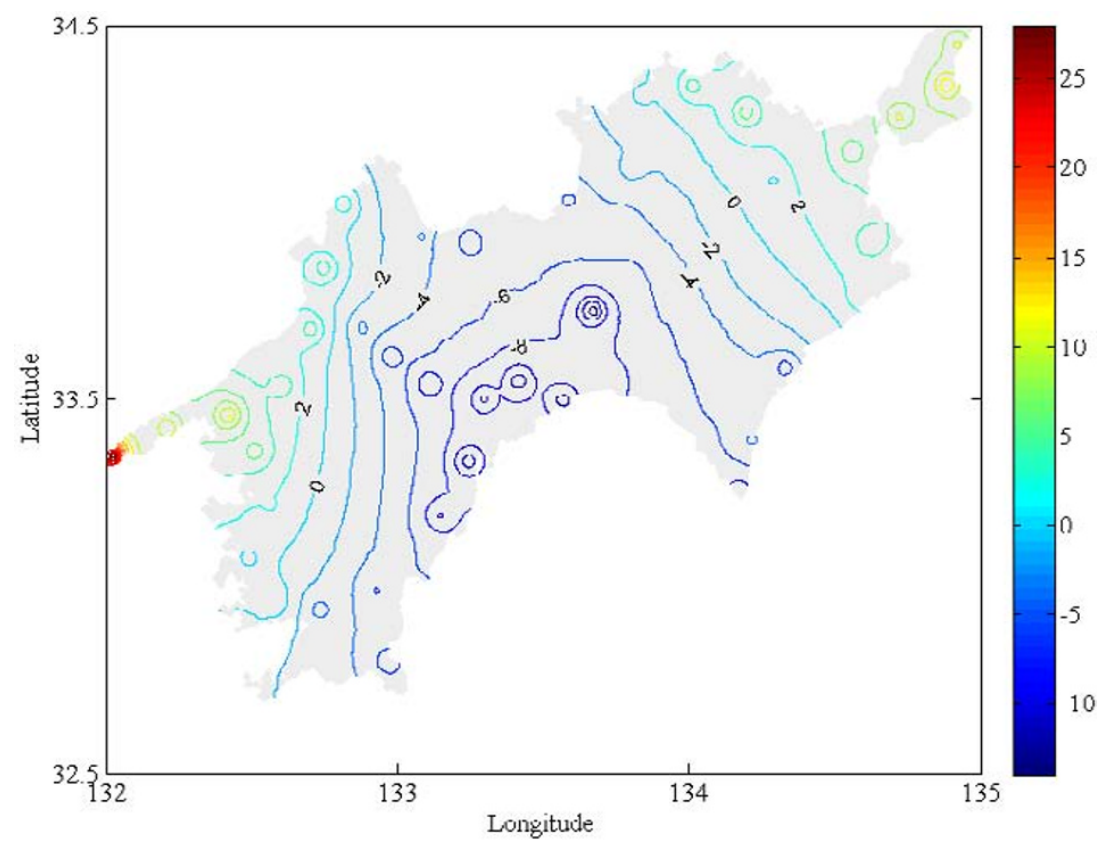

Fig. 2. Differences between the gravimetric geoid (A) and GPS/levelling geoid undulations in Shikoku (units in $\mathrm{cm}$ ).

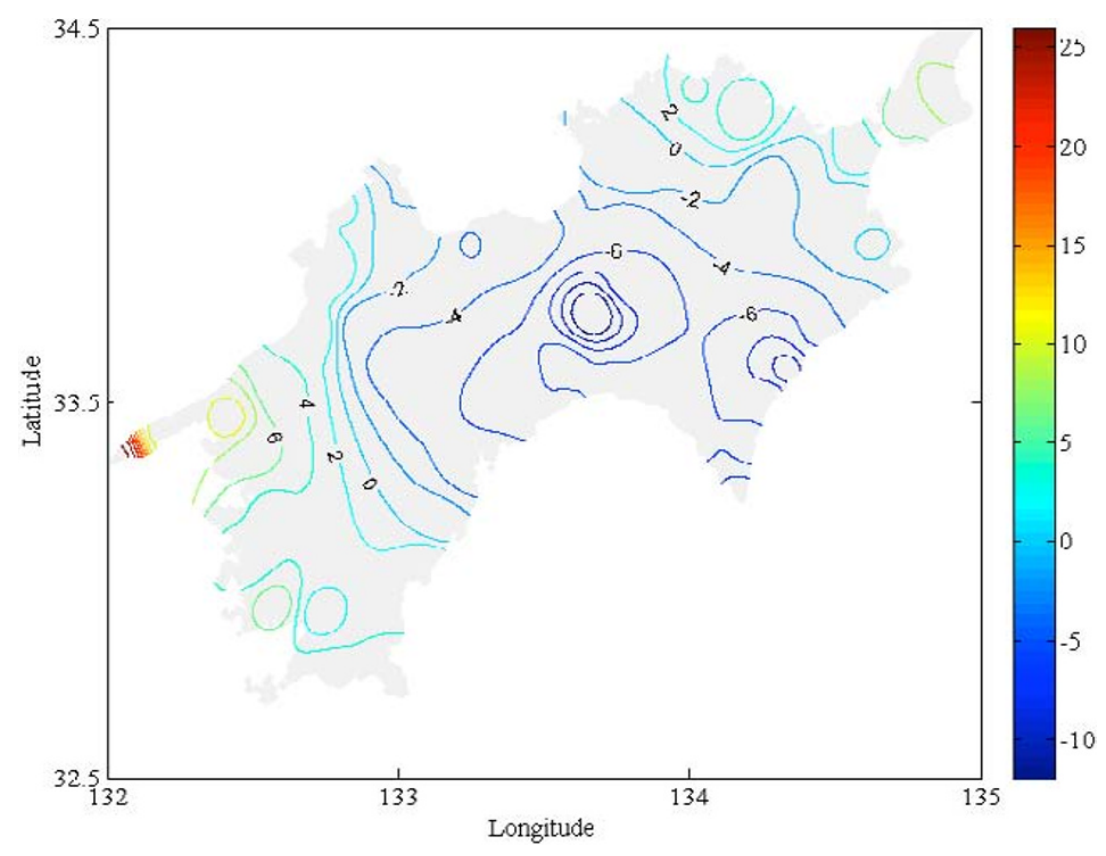

Fig. 3. Differences between the gravimetric geoid (B) and GPS/levelling geoid undulations in Shikoku (units in cm).

Shikoku area.

Two gravimetric geoid models on a 1 by 1.5 arcminute grid covering the Shikoku area are developed from EGM2008 and GOCE-TIM3/EGM2008, incorporating the contribution of the local gravity data. There is an improvement in the standard deviation from \pm 8.7 $\mathrm{cm}$, when EGM2008 is used, to $\pm 6.6 \mathrm{~cm}$, when GOCETM3/EGM2008 is used. There are good prospects for the improvement of the geoid model over Japan by GOCE data at the end of the mission. The improved geoid model(s) from the GOCE data will contribute to efforts towards the unification of vertical datums at national, regional and global levels.
Acknowledgments. We would like to thank the Geospatial Information Authority of Japan for providing GPS/levelling data covering the four main islands of Japan, and other additional data sets. We appreciate the efforts of Nagoya University and other organizations for developing and providing a detailed gravity database covering south-western parts of Japan. We would also like to thank the anonymous reviewers for their constructive comments and suggestions.

\section{References}

Bruinsma, S. L., J. C. Marty, G. Balmino, R. Biancale, C. Förste, O. Abrikosov, and H. Neumayer, GOCE Gravity Field Recovery by means of the Direct Numerical method, ESA Living Planet Symposium 2010, Bergen, Norway, June 27-July 2, 2010.

Goiginger, H., E. Höck, D. Rieser, T. Mayer-Gürr, A. Maier, S. Krauss, 
R. Pail, T. Fecher, T. Gruber, J. M. Brockmann, I. Krasbutter, W. D. Schuh, A. Jäggi, L. Prange, W. Hausleitner, O. Baur, and J. Kusche, The combined satellite-only global gravity field model GOCO02S, General Assembly of the European Geosciences Union 2011, Vienna, Austria, April 4-8, 2011.

Gruber, T., P. N. A. M. Visser, Ch. Ackermann, and M. Hosse, Validation of GOCE gravity field models by means of orbit residuals and geoid comparisons, J. Geod., 85, 845-860, 2011.

Heiskanen, W. A. and H. Moritz, Physical Geodesy, Freeman and Company, San Francisco, 1967.

Hirt, C., T. Gruber, and W. E. Featherstone, Evaluation of the first GOCE static gravity field models using terrestrial gravity, vertical deflections and EGM2008 quasigeoid heights, J. Geod., 85, 723-740, 2011.

Janák, J. and M. Pitoňák, Comparison and testing of GOCE global gravity models in Central Europe, J. Geod. Sci., 1, 333-347, 2011.

Krige, D. G., A statistical approach to some basic mine valuation problems on the Witwatersrand, Journal of the Chemical, Metallurgical and Mining Society of South Africa, 52, 119-139, 1951.

Kuroishi, Y., Improved geoid determination for Japan from GRACE and a regional gravity field model, Earth Planets Space, 61, 807-813, 2009.

Kuroishi, Y. and W. Keller, Wavelet approach to improvement of gravity field-geoid modelling for Japan, J. Geophys. Res., 110, B03402, doi:10.1029/2004JB003371, 2005.

Kuroishi, Y., H. Ando, and Y. Fukuda, A new hybrid geoid model for Japan, GSIGEO 2000, J. Geod., 76, 428-436, 2002.

Lemoine, F. G., D. E. Smith, L. Kunz, R. Smith, E. C. Pavlis, N. K. Pavlis, S. M. Klosko, D. S. Chinn, M. H. Torrence, R. G Williamson, C. M. Cox, K. E. Rachlin, Y. M. Wang, S. C. Kenyon, R. Salman, R. Trimmer, R. H. Rapp, and R. S. Nerem, The development of the NASA GSFC and NIMA joint geopotential model, in Gravity, Geoid and Marine Geodesy, IAG Symposia, edited by J. Segawa, H. Fujimoto, and S. Okubo, 117, 461-469, Springer, 1997.

Martinec, Z. and P. Vaníček, The indirect effect of topography in the Stokes-Helmert technique for a spherical approximation of the geoid, Manuscr. Geodaet., 19, 213-219, 1994a.

Martinec, Z. and P. Vaníček, Direct topographical effect of Helmert's condensation for a spherical approximation of the geoid, Manuscr. Geodaet., 19, 257-268, 1994b.

Meissl, P., Preparations for the numerical evaluation of second-order Molodensky-type formulas, Report No. 163, Department of Geodetic Science \& Surveying, Ohio State University, Columbus, 1971.

Migliaccio, F., M. Reguzzoni, A. Gatti, F. Sansò, and M. Herceg, A GOCEonly global field model by the space-wise approach, 4th International
GOCE User Workshop 2011, Munich, Germany, March 31-April 1, 2011.

Moritz, H., Advanced Physical Geodesy, Wichmann Verlag, Karlsruhe, 1980.

Odera, P. A., Y. Fukuda, and Y. Kuroishi, A high-resolution gravimetric geoid model for Japan from EGM2008 and local gravity data, Earth Planets Space, 64, 361-368, 2012.

Pail, R., H. Goiginger, W. D. Schuh, E. Höck, J. M. Brockmann, T. Fecher, T. Gruber, T. Mayer-Gürr, J. Kusche, A. Jäggi, and D. Rieser, Combined satellite gravity field model GOCO01S derived from GOCE and GRACE, Geophys. Res. Lett., 37, L20314, doi:10.1029/2010GL044906, 2010a.

Pail, R., H. Goiginger, R. Mayrhofer, W. D. Schuh, J. M. Brockmann, I. Krasbutter, E. Höck, and T. Fecher, Global gravity field model derived from orbit and gradiometry data applying the time-wise method, ESA Living Planet Symposium 2010, Bergen, Norway, June 27-July 2, 2010 b.

Pail, R., S. Bruinsma, F. Migliaccio, C. Förste, H. Goiginger, W. D. Schuh, E. Höck, M. Reguzzoni, J. M. Brockmann, O. Abrikosov, M. Veicherts, T. Fecher, R. Mayrhofer, I. Krasbutter, F. Sansò, and C. C. Tscherning, First GOCE gravity field models derived by three different approaches, J. Geod., 85, 819-843, 2011.

Pavlis, N. K., S. A. Holmes, S. C. Kenyon, and J. K. Factor, An Earth gravitational model to degree 2160: EGM2008, the 2008 General Assembly of the European Geosciences Union, Vienna, Austria, April 1318, 2008.

Rapp, R. H., Y. M. Wang, and N. K. Pavlis, The Ohio State 1991 geopotential and sea surface topography harmonic coefficient models, Report No. 410, Department of Geodetic Science and Surveying, Ohio State University, Columbus, 1991.

Stokes, G. G., On the variation of gravity on the surface of the Earth, Trans. Cambridge Phil. Soc., 8, 672-695, 1849.

Tapley, B., J. Ries, S. Bettadpur, D. Chambers, M. Cheng, F. Condi, B. Gunter, Z. Kang, P. Nagel, R. Pastor, T. Pekker, S. Poole, and F. Wang, GGM02C-An improved Earth gravity field model from GRACE, $J$. Geod., 79, 467-478, 2005.

Wichiencharoen, C., The indirect effects on the computation of geoid undulations, Report No. 336, Department of Geodetic Science and Surveying, Ohio State University, Columbus, 1982.

P. A. Odera (e-mail: podera@jkuat.ac.ke) and Y. Fukuda 